\title{
Common factors in the withdrawal of European aircraft manufacturers from the regional aircraft market
}

\author{
Hans Heerkens ${ }^{\mathrm{a}}$, Erik J. de Bruijn ${ }^{\mathrm{a}}$ and Harm-Jan Steenhuis ${ }^{\mathrm{b} *}$ \\ ${ }^{a}$ School of Management and Governance, University of Twente, The Netherlands; ${ }^{b}$ College of Business and Public \\ Administration, Eastern Washington University, USA
}

\begin{abstract}
We investigate whether there were common causes for the withdrawal from the regional aircraft market of three established manufacturers (BAE Systems, Fokker and Saab), while competitors thrived. We focus on the markets for 50- and 100-seat aircraft. One cause concerning the 50-seat market was the introduction of a new class of aircraft, the regional jet, which pushed the less successful turboprop aircraft from the market. Turboprop aircraft that had been relatively successful before the introduction of regional jets survived. A probable reason for the withdrawal of BAE Systems and Fokker from the 100-seat market (in which Saab was not present) was that their products were 'standalone' aircraft, while those of their successful competitors were members of aircraft families, the larger members being far more successful. It was not the availability of technology that determined the success of regional aircraft manufacturers, but the application of (suppliers') technology in new products.
\end{abstract}

Keywords: aerospace industry; regional jet market; withdrawal strategy

\section{Introduction}

For students of corporate strategy, there is an abundance of literature on factors that influence the success or failure of individual companies or products; see, for example, Johnson and Scholes (1999) and Kerzner (2003). On the level of markets and industries, much research has also been done; see Hanlon (1996) and Doganis $(2002,2003)$. In this contribution, we focus on the intermediate situation: not one but a number of companies find themselves taking the same strategic decision, but the industry as a whole does not share that course of events. In the past decade, three established European producers of so-called regional aircraft ${ }^{1}$ closed their production lines for this type of aircraft. Fokker in the Netherlands went bankrupt in 1996 and ceased producing aircraft altogether. It is now part of the Dutch Stork engineering group and makes parts and subsystems for aerospace companies such as Airbus and Boeing. Saab and BAE Systems (formerly British Aerospace) stopped producing regional aircraft and concentrated on military planes and subsystems. Other companies such as Franco-Italian ATR and Bombardier from Canada, however,

\footnotetext{
*Corresponding author. Email: hsteenhuis@mail.ewu.edu
} 
continued to prosper. Embraer from Brazil, a new entrant in 1996, even became the market leader for a new class of regional aircraft; the regional jets. The similar course of events at BAE Systems, Fokker and Saab in such a short time span raises the question whether common factors played a role. If these can be identified, important lessons for other companies and, ultimately, other industries may be learned. So, our problem statement is: what were the common (as opposed to company-specific) factors that contributed to BAE Systems, Fokker and Saab leaving the regional aircraft market in the 1990s?

In this contribution, we examine the regional aircraft market in the period 1990-2005 from the perspective of the competitive forces at work in the industry, using Porter's (1980) five forces model as a means of defining groups of actors and their influence on BAE Systems, Saab and Fokker. The components of this model are summarised in the third section after addressing the scientific and practical relevance of our study. The fourth section continues the literature review on the regional aircraft industry and also lists the reasons for market withdrawal known in the literature. Our method of research is addressed in the fifth section and the results are presented in the sixth section. The last section contains the conclusions, practical implications and recommendations for further research. ${ }^{2}$

Our focus is to find common causes operating in a specific situation in a specific time period affecting a group of companies within the regional aircraft industry, while excluding factors that might have influenced individual companies only. The domain of our research is visualised by the grey area in Figure 1. Variables $X$ and $Y$ have values that are either unique for each company or are not related to success or failure anyway. Examples are company culture (a potential critical success factor but unique for each company) and identity of clients; some successful and failed companies may share the same clients. Also, purely internal factors such as development and production problems or conflicting management priorities belong to this category. These variables fall outside the scope of this article but are worthy of further elaboration in a future contribution.

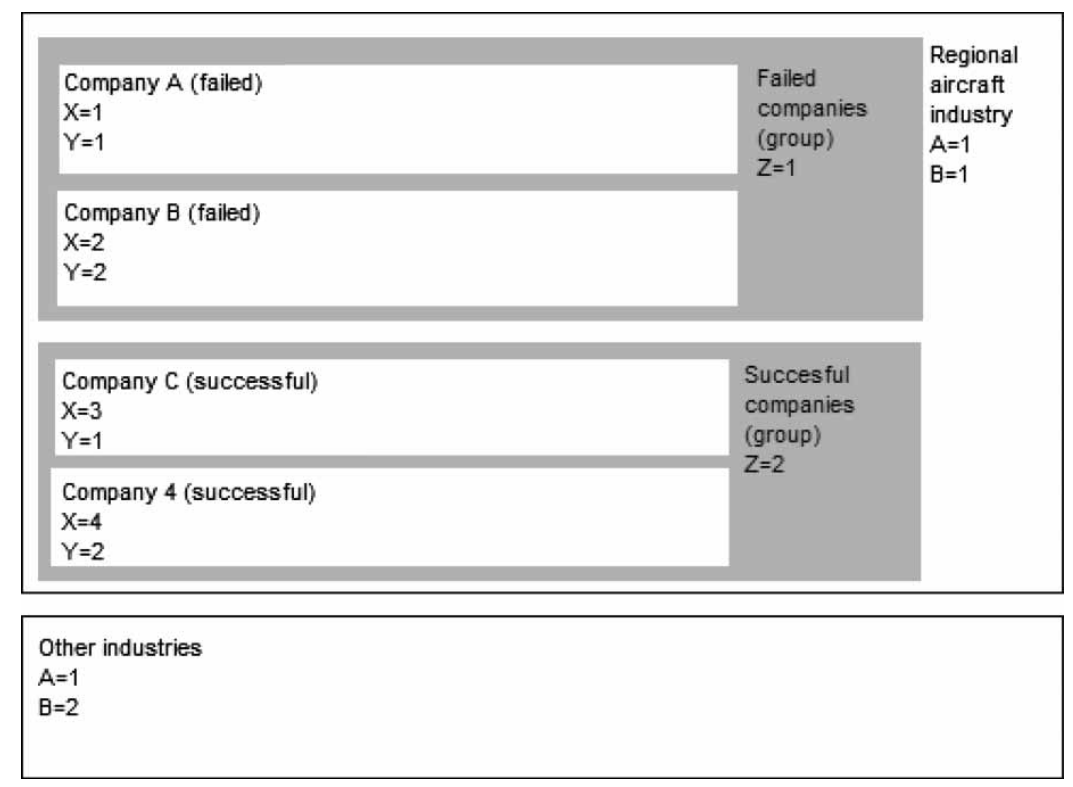

Figure 1. Research domain. 
Our focus is on variables like $Z$, which have one value for failed companies and a different one for successful companies. Suppose, for example, that failed companies are always small and successful companies are always large. There are also variables that have the same value for the whole regional aircraft industry, and the same $(A)$ or different $(B)$ values for other industries. One can think of the level of internationalisation in which the car and regional aircraft industries are probably similar, and of the numbers of units produced in which manufacturers in the regional aircraft industry differ widely from those in the car industry. We will not deal with these variables.

\section{Scientific and practical relevance}

The scientific relevance of our work is that it shows that looking at a group of companies can reveal causal relationships that remain hidden if one looks just at individual organisations. Furthermore, this article brings together a number of possible causes of one of the most dramatic shake-ups in the aerospace industry in the past 40 years, one that has not been analysed in its totality before. Some causes that were hitherto assumed in, for example, the trade press, will be systematically explored and related to each other.

The last point also touches the practical relevance of our study. The development of complex capital goods like aircraft involves continuous choices about which technology to apply. For executives seeking to position themselves within an industry by choosing the appropriate technologies as instruments of competition, our work may be of interest.

\section{Literature review: the regional aircraft industry and market withdrawal}

The literature review is done in four parts. First, a general description of the regional aircraft industry will be given. Then the actors and forces in the industry are described, after which some important market developments are discussed. Finally, reasons for market withdrawal will be discussed.

\section{The regional aircraft industry: regional aircraft}

Regional aircraft are primarily used for the following types of routes:

- 'Feeder' routes between smaller airfield and large 'hub' airports. For example; there are no direct connections between Edinburgh and Tokyo, so passengers would first have to travel to, say, London Heathrow with a regional aircraft, and then board a (usually large) long-distance aircraft to fly on to Tokyo. In this way, routes that do not yield enough passengers for large aircraft can still be flown economically.

- 'Point-to-point' routes over distances from 300 to $2000 \mathrm{~km}$ between destinations that warrant no larger aircraft and that are so widely separated that at least some travellers prefer aircraft to trains or cars.

Generally, fewer regional aircraft than large long-distance aircraft are sold. For example, in 2007, 707 regional aircraft were sold against 2881 large aircraft (Kingsley-Jones 2008a,b). Still, the regional aircraft market is interesting enough to attract a relatively large number of players. While there are only two major manufacturers of large aircraft (Boeing and Airbus), there were in the 1990s six producers of regional aircraft: BAE Systems, Fokker, Saab ATR, Bombardier and Embraer, not counting Dornier (making 35-seat aircraft) and aspiring companies like Indonesia's 
IPTN. While the US was - and is - in the forefront of the development of many types of aircraft such as large airliners, combat and naval planes, there was and is no US producer of regional aircraft. Still, North America provides the largest markets for these planes (60\% of the total).

\section{The regional aircraft industry: actors and forces}

Porter's (1980) five forces model describes the competitive forces at work in an industry. As the model is well known, we will describe the forces only briefly. We use Porter's model only as a means of distinguishing the various groups of actors that generated the factors influencing the course of events at BAE, Fokker and Saab. We could have used other means of structuring the players in the regional jet market, but Porter's model is well established and fitted our purpose. Also, Ferreri (2003), on whose work we base our analysis of the regional aircraft industry, uses this approach.

Porter's groups of actors executing the five forces are:

\section{(1) Suppliers}

These provide resources such as raw materials and semi-finished goods. Main suppliers in the aerospace industry are airframe (fuselage, wings), engine and avionics (aviation electronics) manufacturers. While there are worldwide only a few handfuls of 'primes', such as Boeing and Airbus, there are hundreds of large and small suppliers. Primes are almost inevitably also suppliers. Suppliers often deliver to competing companies. Also, competitors in one market can be partners in another.

This market structure means that technology coming from suppliers is available to all players that can afford it and have the means to utilise it, at least in the civil aircraft market.

\section{(2) Buyers}

Buyers of the regional aircraft are mainly airlines. Some regional aircraft were - and are - sold to the military, but those numbers were limited.

The total production run of an aircraft, regional or otherwise, consists mainly of a limited number of large orders (from 20 up to 50 or more) from a small number of airlines. This gives buyers large bargaining leverage. Leasing companies place even bigger orders.

\section{(3) Competitors}

At the time, relevant competitors were a limited number of Western aircraft builders: Saab, Fokker and BAE Systems themselves, Avions de Transport Régional (ATR, an alliance of Aerospatiale from France and Italian Alenia), Bombardier (Canada), and Boeing and McDonnell Douglas (the latter now part of Boeing) from the USA. Other Western manufacturers built smaller aircraft not relevant for our study (for example: CASA from Spain and Beechcraft from the USA). NonWestern manufacturers such as Yakovlev and Ilyushin from the former USSR had not penetrated the Western market to any meaningful extent.

The following characteristics of the aerospace industry make competition severe (Ferreri 2003): high cost of production, recurrent excess production capacity (partly because of government support preventing the shedding of excess capacity), height of the exit barrier, differences in strategies resulting in diversification of the rules of the game, and strong dependence on macroeconomic variables (growth of world trade, price of oil) leading to severe peaks and lows in demand of air travel and thus, aircraft.

\section{(4) New entrants}

According to Ferreri (2003), as a result of the technological complexity of aircraft and their high development cost, a minimum size is required for entering the market, both of the manufacturer 
involved and of the country supporting it. While the technological capability and required level of industrialisation are comparable for regional and large aircraft, the economic effort required for developing regional aircraft is considerably less (Ferreri 2003, 46). Economies of scale, technological and market risks (uncertainty in break-even point and number of eventual deliveries), the learning effect and the cost of converting from other products than aircraft create high entry barriers.

In 1996, Embraer from Brazil entered the regional jet market. Although the company had previously built turboprop aircraft with up to 30 seats, and military planes, the 50-seat market was new to it. Embraer is therefore a new entrant.

Germany's Dornier (later Fairchild Dornier and later still Avcraft) introduced a 30-seat regional turboprop aircraft which was subsequently developed intro a twin-engined jet, the 328JET. These aircraft are not relevant for this article owing to their size. In 1998 the company started the development of an all-new family of three regional jets, varying in capacity from 55 to 95 seats. After continued financial difficulties and several changes of ownership the company ceased production of regional aircraft in 2004 without having delivered a single product of this new family.

\section{(5) Substitute products}

For regional aircraft, flying distances between 200 and $1000 \mathrm{~km}$, the primary substitute good is the train, especially the high-speed train (Heerkens 1996). This is also shown by the notion of regional airline representatives that rail transport is subsidised and regional air transport is not, creating a non-level playing field (Doke and Moxon 2000; Wastnage 2002). Rail transport is also the mode of transport that has probably affected air transport the most in the period under study, compared with road transport (Heerkens 1996; Doke and Moxon 2000).

The above forces all influenced the three companies under study, but the regional aircraft industry operates in a wider environment, important elements of which are the customers of the airlines that operate regional aircraft, and the governments of the countries where manufacturers, suppliers and buyers are located.

Airlines will be partly guided by the perceived preferences of their customers when acquiring aircraft, but customers have no direct contact with aircraft manufacturers. They are therefore not considered in this study.

Governments are important since most, if not all, aircraft manufacturers receive government support in one form or another, in the form of development grants, direct investment (shares), tax breaks, export help and so on, as the continuing dispute about aircraft subsidies between Europe and the USA indicates (Aboulafia 2005). It is, however, extremely difficult, if not impossible, to assess the amount of support given. Furthermore it is difficult to distinguish cause from effect. Did the Dutch government stop supporting Fokker in 1996 because its planes did not sell well enough, or was production stopped because government support was no longer forthcoming (Heerkens and Ulijn 2000)? Wall and Flotau (2006) show that there are many sufferings that subsidies can not cure. For these reasons, and because all companies in the regional aircraft industry receive support and it is hence not an a priori discriminating factor, we exclude government support from our analysis.

The above gives us some important clues to look for when assessing why BAE Systems, Fokker and Saab failed while others prospered: competing products that translate technical quality and innovation into a cost advantage, and power distribution between clients, suppliers and primes. Factors such as the growth of world trade are less interesting because they are the same for all players in the industry.

We conclude this section by giving some broad market development in the 1990s for the regional aircraft industry. 


\section{The regional aircraft industry: market developments}

The first important development is deregulation, called liberalisation in Europe see (Hanlon 1996; Doganis 2002, 2003). This means the abolition of rules set by governments concerning ticket prices, flight frequencies, aircraft capacity and so on. Since deregulation, which started in the US in 1978 and in Europe in the 1990s, airlines can, within the two economic blocks, fly any route, with aircraft of any size, and ask any ticket price, airport slot capacity permitting, provided they observe safety, environmental and antitrust rules. The unification of Europe, essentially making national borders within European Community members irrelevant, made international regional routes much easier to set up, an important boost for the industry given that many EU-countries are too small for viable domestic networks. Both in the USA and Europe, regional airlines increasingly started to feed the hub-and-spoke systems of major (network) airlines. This gave these network carriers the opportunity to expand their international routes, the area in which they could best compete.

The second major development, as far as regional aviation was concerned, was the emergence of the regional jets: 50-70 seat aircraft not fitted with turboprop engines, as was normal at the time, but with jet engines. We will discuss this issue at length later. The emergence of the regional jets coincided with a sharp decline in deliveries of regional turboprop aircraft (see Table 5).

A constant factor since the Second World War is the structural growth of the industry. Bar one or two exceptions such as 1991 (the year of the first Gulf War), air transport has grown some 5\% per year in terms of revenue passenger kilometres. This, together with deregulation, gave great opportunities for regional airlines both in the USA and in Europe, while attracting new prospective aircraft manufacturers, primarily in the regional sector because of its lower entry barriers.

This concludes our short overview of the regional aircraft market. It has given us some clues as to where to look for explanations for the demise of BAE Systems, Fokker and Saab, and has given us a general picture of the market in which to fit the rest of this article.

\section{Reasons for market withdrawal}

Various reasons are given why a company would want or need to withdraw from a market (Dasgupta and Stiglitz 1981; Karakaya 2000; Pauwels and Matthyssens 2002). Johnson and Scholes (1999) summarise them as follows:

(1) Inability to secure the resources or competence level of the leader in the market overall or the niches or segments in the market. For example, British manufacturers of large passenger aircraft could not match products of Boeing and Douglas from the USA in the 1960s (partly because of swept-wing technology, see Irving 1993) and no such British plane was produced after the Vickers VC10 of the 1960 s. $^{3}$

(2) Changes in the intrinsic value of a product over time. For example: with the introduction of electricity and the internal combustion engine, the intrinsic value of coal diminished.

(3) A shifting of priorities, for example when resources are diverted to more promising products.

(4) Expectations of dominant stakeholders, who for example want to focus on markets with potential quick profits vs long-term results.

(5) Expectations of the stock market. If activities in a particular market do not generate the rate of return shareholders demand, this may be a reason for withdrawal.

(6) A management buy-out, for example in the wake of a privatisation. The newly-structured company may embark on a strategic refocus. 
Karakaya (2000) draws attention to factors that discourage exit. An important exit barrier for the aerospace industry is cost of divestment such as write-off of development costs and production tools, compensation claims from clients because of a perceived or real drop in residual value of their aircraft, loss of goodwill, loss of income from maintenance and support services and so on. It is conceivable that these factors delayed the exit of some companies considerably but they obviously did not alter the fact that the three companies exited the market.

\section{Research method}

A literature study was used to identify possible factors that led to the discontinuation of the production of regional aircraft at Fokker, BAE Systems and Saab. We also searched for those factors during interviews, at the time and afterwards, with representatives of the companies under concern. We talked to several marketing managers, strategists and airline analysts from these companies, to a few representatives from Embraer and Bombardier, and to some experts in marketing and strategy outside the aerospace sector.

The data collection resulted in a list of possible factors that caused the withdrawal of the companies from the regional aircraft market. The next step was to assess for each of these factors whether it was company-specific or not. Then, it was assessed whether possible common factors were not, in fact, industry-wide problems. Finally, the factors labelled as 'common causes' were, as far as possible, quantified and the exact causal chain that defined the influence of each variable was established through literature study.

\section{Results: market forces}

For each of Porter's (1980) five forces the key issue is whether that force entailed common causes in the withdrawal of Fokker, Saab and BAE Systems from the regional aircraft market.

\section{Suppliers}

The three companies shared common suppliers, but for major subsystems the suppliers varied. For example, Table 1 shows the suppliers of the engines for each of their regional aircraft (Taylor 1989; Gould 2005). In the table some of the main characteristics of the aircraft are included for a better understanding of the remainder of this article. Many other suppliers play a role, but the engine is often the most costly subsystem, and the most difficult to change in an aircraft design, so the engine supplier potentially has a profound effect on the success of an aircraft programme.

From Table 1, it appears unlikely that actions by a single supplier could bring down all products of a single company, let alone the products of the three companies together. There were various engine suppliers and no indications of monopolies. All programmes, with the possible exception of the Saab 2000, were mature at the time they were stopped. So there is no reason to believe that the quality or cost of suppliers as such was a common cause. In terms of both engine and avionics technology, there is no reason to suppose that these technologies were selectively available to some manufacturers and not to others. We conclude that the competitive force executed by suppliers had equal effects for all regional aircraft manufacturers and do not explain why BAE, Fokker and Saab left the market while others survived. The successful competitors used the same suppliers: ATR used Pratt \& Whitney Canada, Embraer, Boeing and Airbus used mainly jet engines built by General Electric and SNECMA (France), Bombardier used both. 
Table 1. Main characteristics of regional aircraft built by BAE Systems, Fokker and Saab and engine suppliers.

\begin{tabular}{|c|c|c|c|c|c|}
\hline Aircraft type & $\begin{array}{l}\text { Type (number) } \\
\text { of engines }{ }^{a}\end{array}$ & $\begin{array}{l}\text { Number } \\
\text { of seats }\end{array}$ & $\begin{array}{l}\text { Year of first } \\
\text { flight }\end{array}$ & $\begin{array}{l}\text { Developed from } \\
\text { (first flight) }\end{array}$ & $\begin{array}{l}\text { Supplier of } \\
\text { engine }\end{array}$ \\
\hline BAE Systems ATP & Turboprop (2) & 64 & 1986 & Avro 748 (1960) & Pratt \& Whitney Canada \\
\hline $\begin{array}{l}\text { BAE Systems BAe } \\
\text { 146/RJ/RJX }\end{array}$ & Jet (4) & $73-100$ & 1983 & - & Honeywell \\
\hline Fokker 50 & Turboprop (2) & 50 & 1985 & F27 (1955) & Pratt \& Whitney Canada \\
\hline Fokker 70/100 & Jet (2) & $79-107$ & 1986 & F28 (1967) & Rolls-Royce \\
\hline Saab 340 & Turboprop (2) & 37 & 1983 & - & General Electric \\
\hline Saab 2000 & Turboprop (2) & 50 & 1992 & Saab 340 (1983) & Alison (now Rolls-Royce) \\
\hline
\end{tabular}

${ }^{a} \mathrm{~A}$ turboprop engine is a jet engine driving a propeller.

Table 2. Numbers of regional aircraft delivered until 2005 by BAE Systems, Fokker and Saab.

\begin{tabular}{lc}
\hline Aircraft type $^{a}$ & Number delivered \\
\hline BAE Systems ATP & 62 \\
BAE Systems BAe-146 and RJ & 390 \\
Fokker 50 & 212 \\
Fokker 70 and 100 & 324 \\
Saab 340 & 456 \\
Saab 2000 & 60 \\
\hline
\end{tabular}

${ }^{a}$ Versions of the same aircraft but with different designations are taken together.

Sources: Kingsley-Jones (2005b); Gould (2005).

\section{Buyers}

A good indicator of the role of buyers is the number of regional aircraft delivered (see Table 2). A measure of success for individual aircraft programmes is the number of aircraft sold relative to the break-even point: the point at which the revenues of sold aircraft equal the total development and production cost up to that point. An aircraft programme only generates profit after the breakeven point is passed. The problem is that the break-even point is a closely guarded secret. In the literature and in conversations with aerospace executives we came across figures from 60 for a new version of an aircraft to 500 for a completely new aircraft, but no definitive figures are available.

Table 2 lists actual deliveries of the different aircraft. ${ }^{4}$

In conclusion, there were three seemingly reasonably successful aircraft (Saab 340, BAe146/RJ and Fokker 100), plus two failures (ATP and Saab 2000), with the Fokker 50 in the balance. Before a definitive judgement on the success of these aircraft can be established, we will first look at the competitors and new entrants.

\section{Competitors}

Generally, the regional aircraft market can be segmented on two criteria: number of seats and type of propulsion. Range is also relevant, but generally the range of regional aircraft meets or exceeds 
Table 3. Market segmentation of main types of regional aircraft.

\begin{tabular}{lcccc}
\hline & 50 seats & 70 seats & 85 seats & 100 seats or more \\
\hline Turboprop & Fokker 50 & ATR72 & None & None \\
& ATR42 & ATP & & \\
& Dash 8-300 & Dash 8-Q400 & & \\
Jet & CRJ100/200/440 & BAe-146-100 & BAe 146-200/RJ70 & BAe RJ85/RJ100 \\
& ERJ140/145 & CRJ700 series & CRJ900 series & Fokker 100 \\
& & ERJ170 (2004 on) & ERJ175 (2004 on) & MD-87/Boeing 717 \\
& & Fokker 70 & & Boeing 737-500/600 \\
& & & ERJ190/195 (2005 on) \\
\hline
\end{tabular}

Table 4. Numbers of regional aircraft delivered until 2005 by the competition.

\begin{tabular}{lc}
\hline Aircraft type $^{a}$ & Number delivered \\
\hline Airbus A318 & 25 (779 if 124-seat A319 is included) \\
ATR42 and 72 & 680 \\
Boeing MD87 and 717 & MD87 not available, 717: 146 \\
Boeing 737-500 and -600 & Approx. 443 \\
Bombardier Dash 8 & 716 \\
Bombardier CRJ100, 200 and 440 & 1013 \\
Bombardier CRJ 700 and 900 & 253 \\
Embraer EMB140 and 145 & 843 \\
Embraer ERJ170, 175, 190 and 195 & 92 \\
\hline
\end{tabular}

${ }^{a}$ Versions of the same aircraft but with different designations are taken together. Sources: Kingsley-Jones (2005b); Gould (2005).

demands for routes where a certain capacity is required. As routes get longer, propeller planes are replaced by jets, so there is a relationship between route length and mode of propulsion. As there are only a limited number of sizes available, generally an airline has to choose between a 50-seater, a 70-seater, an 85-90-seater and a 100-110-seater. The segmentation of regional aircraft according to size and powerplant is depicted in Table 3.

A first issue is to compare competitors to BAE Systems, Fokker and Saab. In Table 4, total numbers of aircraft delivered are shown until 2005. In Table 4, as far as jets are concerned, 50-seat and 70-100-seat aircraft are depicted separately. All of the jets in Table 2 fall in the 70-100-seat category.

The combination of Tables 2 and 4 illustrates that Boeing, and to a certain extent Airbus, are considerably more successful in the 100-seat market than BAE Systems and Fokker. ATR and Bombardier are much more successful in the 50-seat turboprop market than BAE Systems, Saab and Fokker. In the following we will show that the relative lack of success points at two common causes; one highly likely and one probably.

For the first common cause we return to the market segmentation depicted in Table 3: turboprop and jet aircraft. In Table 5, the numbers of turboprop and jet aircraft (all types combined) delivered in the period 1991-2004 are shown.

Tables 5 shows an interesting trend: production of turboprop aircraft diminished dramatically in the late 1990s. In the 1980s the turboprop market was very healthy. Of the ATR42 and -72, the 
Table 5. Numbers of regional turboprop and jet aircraft (all types) delivered in 1990-2004.

\begin{tabular}{lccccccccccccccc}
\hline Year & 90 & 91 & 92 & 93 & 94 & 95 & 96 & 97 & 98 & 99 & 00 & 01 & 02 & 03 & 04 \\
\hline $\begin{array}{l}\text { Number of } \\
\text { turboprops }\end{array}$ & 398 & 341 & 251 & 216 & 206 & 244 & 238 & 184 & 154 & 105 & 91 & 78 & 65 & 27 & 36 \\
$\begin{array}{l}\text { Number of jets } \\
\text { number }\end{array}$ & 1 & 1 & 5 & 24 & 30 & 61 & 72 & 88 & 131 & 191 & 283 & 328 & 318 & 304 & 294 \\
\hline
\end{tabular}

Source: Kingsley-Jones (2005a).

most successful turboprop family, 410 aircraft were delivered in the period 1985-1994 (KingsleyJones 2005a). It is now generally accepted in the industry that the introduction of 50-seat regional jets from 1992 onwards caused what some saw as the definitive demise of the turboprop passenger aircraft (Aboulafia 2002; Kingsley-Jones 2005a,b, 2006). The main reasons why regional jets were so in demand in the 1990s are: their higher cruise speed (shortening travelling time and increasing the number of destinations that could be reached within a given flight time), their greater productivity; and the perceived greater comfort and safety compared to turboprop aircraft (Aboulafia 2002; Kingsley-Jones 2005a,b, 2006; Heerkens 2006). Note that the rise of the regional jets was an industry-wide phenomenon. It does not explain why production of the Fokker 50, the Saab 340, Saab 2000 and ATP was stopped, while the Dash 8, ATR42 and ATR72 continued to be built.

The Saab 340 was too small (34 seats) to be directly affected by the coming of the regional jets, but the number of deliveries of all sizes of turboprops went down (Kingsley-Jones 2005a) and Saab concentrated on the ultimately unsuccessful Saab 2000. The ATP had so few orders that it is hard to see how it could have become a success even without the threat of the regional jets. As for the Fokker; it remained in production until Fokker went bankrupt in 1996. The question is then: did Fokker go under (partly) because of lack of success of the Fokker 50? This may have been the case (Heerkens and Ulijn 2000). The Fokker 50 certainly was much less successful than the ATR-series, as can be seen from Table 4. The reasons are likely to be aircraft characteristics such as price/quality ratio (Heerkens and Ulijn 2000). These were individual and not common factors.

Contrary to the Fokker 50, Saab was not forced to stop production of the Saab 340 and 2000 because of calamities such as bankruptcy. It took the decision because 'the production has not been profitable and the demand for turboprops has not been satisfactory' (Saab Group Annual Report 1997). Similar to the Fokker 50 this seems to have been due to aircraft-specific factors. Therefore, a common cause for ceasing production, namely the lack of sales success, may be due to individual factors (aircraft characteristics).

The above may explain why Fokker and Saab stopped production of their turboprop aircraft, but does not make clear why ATR and Bombardier continued. In the case of ATR, the total number of units produced was such that the break-even point should have been passed (although this cannot be said with certainty), so that it was possible for ATR to continue low-rate production as long as orders kept coming in, in the hope of a reversal of fortunes. ${ }^{5}$ Furthermore, ATR harboured the long-time ambition to develop a jet aircraft of its own (Kingsley-Jones 2005a). Since the ATR42 and -72 were the company's only products, stopping production would have deprived Aérospatiale and Alenia of the logical vehicle for developing their jet transport.

As for Bombardier, it could afford to continue production of the Dash 8 since its financial health was assured by the success of its regional jets. Here, too, the company seems to have used a strategy of having several 'irons in the fire' in the market for regional aircraft. 
For Bombardier, its survival was never in doubt, given the success of its regional jets. We do not go into the reasons for the success of these planes, beyond what has already been said. It is clear that the reason for the success of the Canadian aircraft builder was that the market welcomed its products. Bombardier had a not very successful business jet (the Challenger) that had properties such as a wide cabin that made it a logical choice as a basis for a regional jet. Whether Bombardier would have developed a regional jet if the Challenger had not been available is a matter of conjecture. Of course, since Bombardier was the only producer of regional jets until 1996, one can maintain that Bombardier's success played a significant role in the withdrawal of the Fokker 50, Saab 2000 and ATP from the market. If a competitor drove Fokker, Saab and BAE Systems from the 50-70-seat market, it is Bombardier.

After this discussion of the 50-70-seat market, we will now look at the 80-100-seat market. Saab was not active here, but Fokker built the Fokker 100 and the smaller Fokker 70, and BAE Systems produced the BAe-146 (later called Avro RJ). These aircraft initially did not face competition from similar-sized regional jets, although this has since changed with the introduction of the CRJ700, CRJ900, EMB170/175 and EMB 190/195 (Aboulafia 2002). Of the competitors of Fokker and BAE Systems on the 100-seat market, Boeing and Airbus are still active.

McDonnell Douglas was taken over by Boeing in 1996. By that time the MD-87 had given way to the improved MD95, fitted with new engines. In January 2005, Boeing announced that production of this aircraft, now renamed Boeing 717, would be stopped, citing a lack of order potential as the main reason (Norris 2005). One-hundred and fifty-five were ordered (Gould 2005). The other McDonnell Douglas aircraft were already out of production, making the 717 a standalone aircraft.

The other two 100-seaters, the Boeing 737-500 (now superseded by the improved 737-600) and Airbus A318, are still in production. Both planes were developed as smaller derivatives of, respectively, the 737-300 and A320 150-seaters. They make it possible for airlines to have one 'family' of planes, consisting of members with different numbers of seats. Having one family of planes reduces maintenance and training costs. The numbers of planes in service in 2005, respectively 443 (737-500 and -600) and 25 (A318), do not indicate a huge dominance vs the Fokker 100 and BAe 146/ RJ (of all versions respectively 373 and 313 were in service) (Gould 2005; Kingsley-Jones 2005c). The market success of the A318 and 737-500 seems to have been no valid reason for Fokker and BAE Systems to leave the market, especially not since the 737-500/600 have been around about as long as the BAe-146 and Fokker $100 .^{6}$

Fokker, going bankrupt, obviously failed to make money on aircraft production, regardless of the reasonably healthy sales of the Fokker 100 in the first years of production (compared to its competitor from BAE). The Fokker 100 is unlikely to have reached the break-even point, although it may have come a long way. BAE Systems stopped production of the BAe 146/RJ (only shortly after having upgraded it as the Avro RJX-series) in 2001. The reason given in the annual report of BAE Systems in 2001 (p. 11) was that after the attacks on 11 September of that year 'in this deteriorating market environment, regional aircraft production is no longer viable'. The market environment may have been the final push rather than the real reason. The prospects of the aircraft never seemed very bright from the beginning of the 1990s onwards, if only because a four-engined plane is inherently expensive to operate on short and medium distances. Even if there had been no regional jets, the Fokker 100 and 70 would likely have limited the sales prospects of the BAE 146 and its Avro RJ derivatives. Twin-engined versions were considered but never got off the ground, probably because the development cost could not be justified given the age of the basic design.

So, at first sight, there seems to be no direct common cause for the suspension of Fokker 100 and BAe 146 production, but it is striking that all stand-alone aircraft or aircraft that had no 
versions larger than 100 seats (Fokker 100, BAe 146 and Boeing 717, were abandoned while the 'family' aircraft (737-500/600 and A318) are still in production. Several new 100-seat projects were conceived in the last 15 years and almost all came to a halt, the latest being the Bombardier C Series (Warwick 2006a; 2006b). Recently, some new 100-seaters have been developed, such as the Russian Sukhoi Superjet, and the C Series was re-launched last year, but this new development, the results of which have yet to be seen, falls outside the period we are looking at. What the figures also make clear is that the number of 100 -seat aircraft in service is relatively small compared to the number of aircraft in the next-bigger market segment: the 150-seat aircraft. This segment is dominated by the 737-300/400 and Airbus A320, with, respectively, 1776 and 1430 delivered (Kingsley-Jones 2005c). This illustrates that, although Fokker and BAE Systems may, ideally, have been able to sell enough 100-seaters to break even, Boeing and Airbus can afford to sell their 100-seaters at far more favourable terms, amortising development cost over a much larger number of aircraft and exploiting the sales potential of the 'family' benefit.

We conclude that the introduction of the regional jets, in combination with the relatively modest sales success of the Fokker 50 and Saab 2000 plus the absence of other 50-seat products to ride out the onslaught of the regional jets was an important cause for the lack of success of Fokker and Saab on the 50-seat regional aircraft market. The lack of success in the 100-seat market that contributed to the bankruptcy of Fokker and to the abandoning of the BAe 146 may have been partly due to the fact that both had no 150 -seat versions and that the market for 70 - and 100-seat aircraft was relatively small compared to that of, for example, 150-seat aircraft.

Some might argue that the advent of the regional jets is not a new explanation of the demise of Saab, Fokker and BAE. It has indeed been suggested in both the industry itself and in the trade press. We, however, think we can not only give a sound foundation to this explanation, offered so often in the form of speculation, but we also show its relevance in relation to other common factors. Also, we should bear in mind that the explanation is not as straightforward as it seems. Not only did ATR survive without a jet in its product range and did jet-builders Fokker and BAE Systems fail, but the jets that Fokker and BAE Systems built were not direct competitors of the regional jets, and the three companies were so different in terms of size, product portfolio and home market that any common cause of their demise is not inherently straightforward and required in-depth research to find and validate it.

\section{New entrants}

As stated above, with the exception of Dornier (which did not deliver a single aircraft in the categories relevant here), Embraer was the only new entrant in the market for regional aircraft with 50 or more seats. It entered the market in 1996 with its growing regional jet family. In other words, during the first critical years in which the foundation for the success of the regional jets was laid and the fate of Fokker was sealed, Embraer was only present with 'paper aircraft' (aircraft still in development). With the Saab 2000 the situation was different. If Embraer had not decided to build regional jets, Bombardier would have been the only company in the market for some more time (later perhaps more successfully joined by Dornier), but lack of production capacity may have forced some airlines to settle for the Saab 2000. However, it is unlikely, given the obvious success of the regional jets, that Bombardier would have maintained a monopoly or would not have greatly expanded its production capacity. It is equally unlikely that the Saab 2000 would have been able to cope in the long run.

In conclusion, the influence of Embraer on the withdrawal of BAE Systems, Fokker and Saab from the regional aircraft market (the turboprop market in the case of BAE) was thus small and in 
any way indirect, at least in the critical period 1991-1996, but its influence on BAE's decision to stop the Avro RJ programme was potentially as big as that of Bombardier. Not only did Embraer provide the production capacity to bring more regional jets to the market, but the competition with Bombardier likely pushed prices down and thus increased demand for these aircraft. What is more, both Bombardier and Embraer had by this time started to produce larger versions of their original 50-seat regional jets that were direct competitors for the Avro RJ (and would have been for the Fokker 70 and 100 had they still been in production). Embraer is now the market leader in regional jets. Even the threat of the company entering the market, visible long before 1996, may have influenced decision makers at manufacturers and airlines alike.

\section{Substitute products}

Rail transport plays only a limited role in the USA. In Europe the situation is different. Furthermore, great changes took place in the 1990s in the form of the establishment of a high-speed train network (Heerkens 1996). High-density routes flown with much bigger aircraft (150-seats or more) than regional jets would be much more affected since high-speed trains run only between major cities. These aircraft were affected but only temporarily, and currently low-cost carriers operating 150-seat aircraft thank their successes to exactly this type of route (Heerkens 1996; Campbell and Kingsley-Jones 2002). The increased competition from high-speed trains may have induced some airlines to buy regional jets instead of turboprops, but the Saab 2000 should also have benefited and it does not explain why ATR remained in business. All in all, substitute products do not appear to have had a major influence on the withdrawal of Saab, BAE Systems and Fokker from the regional aircraft market.

\section{Results: market withdrawal theory}

To what extent are our results described above in line with the theory about market withdrawal? We will examine each of the reasons for market withdrawal mentioned by Johnson and Scholes (1999).

(1) Inability to secure the resources or competence level of the leader in the market overall or the niches or segments in the market. As we have seen, demand for turboprop aircraft declined steeply in favour of demand for regional jets. It cannot be concluded that Fokker or BAE Systems had any less access to the necessary competencies to enter the regional jet market than Bombardier or Embraer. On the contrary: they had, at least initially, much more knowledge of, and access to, potential customers since these were the same as the customers for their existing jet and turboprop aircraft. They did, however, lack the resources (Fokker) or the will (BAE Systems) to develop a regional jet. Fokker was still recovering from the debts incurred by the development of the Fokker 50 and 100, and needed all resources just to keep production going. Future projects considered together with DASA concerned 100-seat aircraft, not regional jets. With the benefit of hindsight, and with the failure of the ATP in mind, it seems likely that the management of BAE had already made up its mind to leave the regional aircraft market. Both manufacturers were unable to develop a family of aircraft from, say, 90 to 180 seats, as Boeing and Airbus were doing. Both companies were partners in Airbus and it was agreed on a national and European level that Airbus was to be the sole European manufacturer of airliners with 150 seats or more. 
As for Saab; we cannot say whether it would have been possible to additionally develop a regional jet, but it would not have undone the heavy investment made in the Saab 2000 and with the all-important JAS39 Gripen fighter programme in full swing, resources were certainly spread thinly.

(2) Changes in the intrinsic value of a product over time. It cannot be concluded that the intrinsic value of jets like BAE Systems and Fokker built them has structurally decreased. The market for 100-seat standalone aircraft was structurally weak, but the market for 70- to 90-seaters increased since the 1990s and is now much stronger than that of the original 50-seaters (Kingsley-Jones 2007). Also, the market for 50-seat turboprop aircraft is picking up once more, to the benefit of ATR and Bombardier.

(3) A shifting of priorities. This reason does not seem to be valid. The lack of success of the products of Saab, Fokker and BAE Systems, plus the financial difficulties faced by Fokker, were the cause of a shifting in priorities, rather than shifting priorities leading to market withdrawal. Note that all the aircraft built by the three companies were either relatively young (the Saab 2000, Fokker 50 and Fokker 100) or had been upgraded quite recently (BAe146). Also, whereas Saab and BAE Systems had priorities to shift (focusing more in military programmes and systems integration) and still build aircraft, Fokker had no other aircraft programmes than the Fokker 50 and 100. The decision to stop these programmes meant that the company would cease to be an aircraft builder and could only remain active as a supplier.

(4) Expectations of dominant stakeholders. A dominant stakeholder sealed the fate of Fokker. In 1996, DASA withdrew its credit guarantee to suppliers of Fokker. Given the bad financial state of the company, this essentially was the final push into bankruptcy, but this stakeholder action was a consequence of Fokker's difficulties; not a cause. Such action by a dominant stakeholder does not seem to have occurred for the other two companies.

(5) Expectations of the stock market. This was not a common cause, since it played no direct role in the case of Fokker.

(6) A management buy-out. This was no issue for any of the companies concerned.

To conclude, only the first reason as mentioned by Johnson and Scholes (1999) can be seen as a common cause in this industry. So, the common causes of the withdrawal of Saab, BAE Systems and Fokker from the regional aircraft market are not at odds with the typology of Johnson and Scholes (1999).

\section{Conclusion and discussion}

One common cause for the withdrawal of BAE Systems, Fokker and Saab from the regional aircraft market was identified: the emergence of the regional jets. A possible common cause relating to Fokker and BAE Systems jet aircraft may be the fact that their 100-seat aircraft had no versions in the attractive 150 -seat market. While we did not go into factors pertaining to each individual company, we identified one clear boundary between common and individual factors. The (lack of) success of certain aircraft was a common factor, the reasons for differences in aircraft characteristics likely follow from factors unique for each individual company. ${ }^{7}$

It will be observed that we refrain from making a judgement about decisions taken by the management of either the successful or the failed companies. We feel that such judgements add little to our understanding and, with the luxury of the benefit of hindsight, ignores the challenges decision makers faced at the time. Besides, it would give a dilemma. Faulty management decisions, lack of foresight, etc. can only serve as common explanations for the course of events at several 
dissimilar companies if we stay on a very general level. As soon as we attempt to concretise these factors, we immediately are confronted with the individual peculiarities of each company.

Is the exercise of trying to find common, but not industry-wide, causes for events occurring within a limited number of companies scientifically useful? We think it is. It allows a better understanding of a particular industry. Common factors draw attention to aspects in which companies are not unique, and hence encourage the generalisation that is necessary for theory-building. For practitioners, the concept of common factors is valuable, since they may be outside the normally perceived scope of direct influence, but their consequences may be controlled to a certain extent so as to differentiate the company from its competitors. If BAE Systems, for example, had embarked on the development of a regional jet before Embraer did, the company might still be a player in the regional aircraft market. It was already known that management decisions can shape a company's future and that the aerospace industry depends, perhaps more than others, on advanced technology. This research shows that availability of technology need not be the bottleneck, but rather the strategic vision on how to use technological resources that are basically available to all players. We recommend that future research emphasises the different uses of available technology by successful and failed companies, and not merely to the technological resources available within enterprises. In fact, as Lei and Slocum (2005) indicate, competition can sometimes emerge from dissimilar products (in our case: aircraft that are in essential aspects differentiated from existing products). Fokker and BAE Systems focused on mainline aircraft, apparently taking for granted that small, short-range planes would be turboprops. They may have been taken by surprise when Bombardier launched a jet aircraft on what historically was a turboprop market. The combination of a modern, fuel-efficient small jet engine (which at the time sounded like something of a contradiction in terms) and a light business-jet airframe made a new class of aircraft possible. So, companies wanting to be proactive should scout the arena of upcoming technologies continuously, and try to find combinations of technologies that may be either opportunities to themselves or threats in the hands of competitors. It may be sensible to see the above issues in the wider context of the problem of managing aircraft manufacturing companies properly. The struggle of Bombardier to launch the $\mathrm{C}$ Series shows how difficult it is to commit to a decision to develop a new product that amounts to 'betting the company'. The problems of both Boeing and Airbus to bring their new A380 and 787 widebodies to the market make clear that plenty of management problems concerning the application of technology remain to be studied in the aerospace industry.

\section{Notes on contributors}

Hans Heerkens is assistant professor at the School of Management and Governance at the University of Twente, the Netherlands. He teaches on research and problem-solving methodology and on management in the aerospace industry. He also does consultancy work in the aerospace and defence industry.

Erik J. de Bruijn is a professor of International Management. He received his MSc from the University of Massachusetts and a PhD from the University of Twente. Currently he teaches International Business Management at the School of Management and Governance, University of Twente.

Harm-Jan Steenhuis is an associate professor of operations management and chair of the Department of Management at Eastern Washington University. He has a MSc in Industrial Engineering and Management and a PhD in International Technology Transfer. He is currently involved in research on various aspects of technology transfer and aerospace.

\section{Notes}

1. Regional aircraft are planes with a capacity of up to about 100 passengers, mainly used for short routes of up to $1000 \mathrm{~km}$. We confine ourselves to aircraft with 45-100 seats. Reasons for this are that these aircraft were the main 
products of BAE, Fokker and Saab, and that lowering the lower limit would have forced us to incorporate manufacturers such as Beechcraft that did not compete with the above-mentioned companies.

2. We are looking at products made by individual companies, not at the companies as a whole or at the aerospace industries of the countries where these companies are located. We are not looking at national characteristics, such as level of education, as explanations for the course of events at the companies concerned.

3. The German Adolph Busemann published the basics in 1935, and after the Second World War, Boeing based its hugely successful swept-wing technology (B-47 and Boeing 707) on German wartime research, to which the British, by and large, also had access.

4. Table 2 does not show orders because the orders are rather volatile (are cancelled frequently). Deliveries follow orders by only 1-2 years, so for the period studied (BAE systems was the last to leave the regional aircraft market in 2001) deliveries give a good indication of the success of the various aircraft programmers in the relevant timeframe.

5. This revival of turboprop aircraft occurred in 2005 and 2006.

6. The A318 is much newer which partially explains the small numbers in service, but if we include the 124-seat A319 then Airbus is also very successful.

7. Why did BAE Systems, Fokker or Saab not develop a regional jet of their own? This question lies outside the scope of this article but it is an interesting subject for further research.

\section{References}

Aboulafia, R. 2002. Fairchild Dornier: Phoenix into ashes. Aerospace America 40, no. 6: 16-18.

Aboulafia, R. 2005. Boeing's WTO-complaint; the last battle? Aerospace America 43, no. 1: 10-12.

Campbell, A., and M. Kingsley-Jones. 2002. Rebel skies. Flight International 161, no. 4826: 29-39.

Dasgupta, P., and J. Stiglitz. 1981. Entry, innovation, exit. Towards a dynamic theory of oligopolistic industrial structure. European Economic Review 15: 137-58.

Doganis, R. 2002. Flying off course. London: Routledge.

Doganis, R. 2003. The airline business in the 21st century. London: Routledge.

Doke, D., and J. Moxon. 2000. Airways railroaded. Flight International 157, no. 4742: 24-27.

Ferreri, D. 2003. Marketing and management in the high-technology sector: strategy and tactics in the commercial airplane sector. Westport, CT: Praeger.

Gould, I. 2005. Bounce back; world airliner directory, part 2. Flight International 168, no. 5009: 33-63.

Hanlon, P. 1996. Global airlines: competition in a transatlantic industry. Oxford: Butterworth-Heineman.

Heerkens, H. 1996. Naadloos netwerk. In De wereld van KLM in 1996, ed. B. Koster, 42-47. Amstelveen: KLM Bureau Public Relations.

Heerkens, H. 2006. Het jaar van de propeller. Piloot \& Vliegtuig 13, no. 5: 48.

Heerkens, J.M.G., and J.M. Ulijn. 2000. Fokker, a clash of cultures. Journal of Enterprising Culture 7, no. 3: $269-97$.

Irving, C. 1993. Widebody; the making of the Boeing 747. Reading: Cox \& Wyman.

Johnson, G., and K. Scholes. 1999. Exploring corporate strategy. Harlow: Pearson Education.

Karakaya, F. 2000. Market exit and barriers to exit. Theory and practice. Psychology and Marketing 17, no. 8: 651-68.

Kerzner, H. 2003. Project management case studies. Hoboken, NJ: John Wiley.

Kingsley-Jones, M. 2005a. Keeping faith. Flight International 168, no. 5005: 33-35.

Kingsley-Jones, M. 2005b. Turning a circle. Flight International 168, no. 5006: 38-43.

Kingsley-Jones, M. 2005c. Battle ground. Flight International 168, no. 5008: 35-61.

Kingsley-Jones, M. 2006. Turboprops bounce back. Flight International 169, no. 5021: 14-15.

Kingsley-Jones, M. 2007. Regional appetite returns. Flight International 171, no. 5077: 12-13.

Kingsley-Jones, M. 2008a. Airbus is sanguine in defeat. Flight International 173, no. 5122: 10.

Kingsley-Jones, M. 2008b. Props drive regional boom. Flight International 173, no. 5129: 12-13.

Lei, D., and J.W. Slocum. 2005. Strategic and organizational requirements for competitive advantage. Academy of Management Executive 19, no. 1: 31-45.

Norris, G. 2005. Boeing finally pulls the plug on 717. Flight International 167, no. 4968: 4.

Pauwels, P., and P. Matthyssens. 2002. The dynamics of international market withdrawal. Maastricht: METEOR.

Porter, M.E. 1980. Competitive strategy. New York: Free Press.

Taylor, J.W.R. 1989. Jane's all the World's aircraft 1989-1990. Coulsdon: Jane's Information Group.

Wall, R., and J. Flotau. 2006. Mega mess. Aviation Week \& Space Technology 165, no. 14: 26-27.

Warwick, G. 2006a. A niche too far. Flight International 169, no. 5022: 3.

Warwick, G. 2006b. Stretches to fill CSeries void. Flight International 169, no. 5022: 8-9.

Wastnage, J. 2002. Identity crisis. Flight International 162, no. 4851: 40-42. 